\title{
EDITORIAL
}

\section{Teaching Remotely During COVID-19: Opportunities for Creativity and Innovation}

When we were hit by the COVID-19 pandemic in March this year, most of us in schools and higher education were not prepared for what was coming our way in terms of teaching and learning. Schools and campuses were quickly locked down to prevent the spread of the virus, and like a pendulum, education swung from physical to virtual. Universities hurried to develop emergency remote teaching and learning (ERTL) guidelines, and faculty rushed to teach themselves online teaching skills. Google Classroom became a common name in schools and universities as the primary learning management system for materials distribution. Google Forms transformed in use from being just a survey tool to a learning assessment tool. Apps like Edpuzzle and Quizlet came into use as the means for flipping classes.

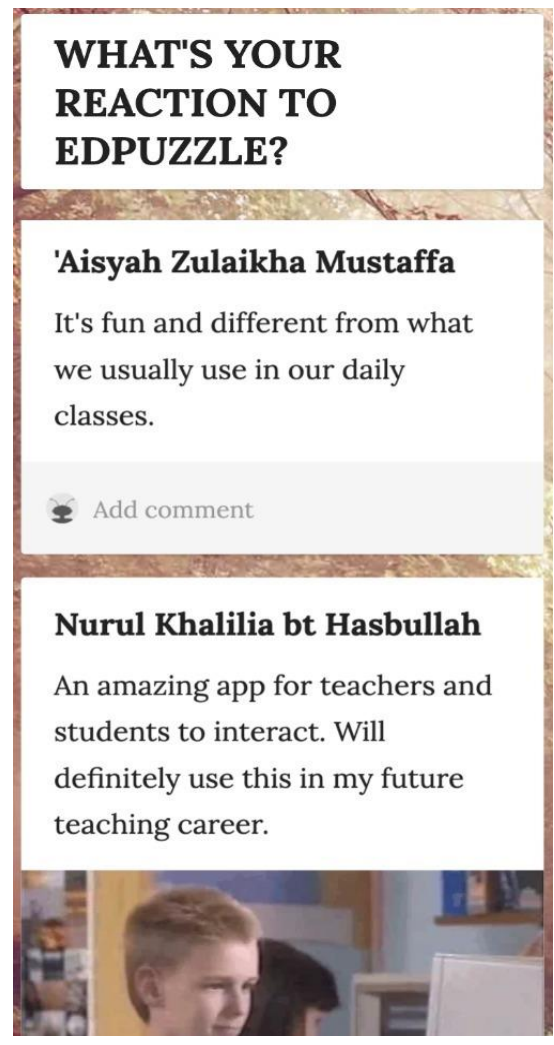

My undergraduate students' reactions to Edpuzzle

WHAT'S YOUR
REACTION TO
EDPUZZLE?
Haznina
It's quite complicated at first
because I've never used it before.
But now, I'm interested to learn
edpuzzle!
= Add comment
NADHAH
It makes me nervous every time
questions came out but it is very
interesting and fun, better than
just all the time listening to the
teacher speaking in the class.

The adoption of Zoom and Google Meet was swift. These platforms were little known to students and lecturers just a few months prior.

Everett M. Rogers (author of Diffusion of Innovations, 2003) would have been amazed, or perhaps even amused, at how fast people can become innovators (i.e., technology savvy people who are always at the forefront of technology adoption) and early adopters (i.e., 
knowledgeable opinion leaders whose decisions about technology tend to influence the path taken by other technology users) in just a matter of weeks.

Then there are laggards - those that are slow, hesitant and reluctant in innovation adoption. Quite unfortunately, the exigency for ERTL during the pandemic has no mercy on them. The demands are non-negotiable. Laggards won't survive the onslaught of this new face of education created by COVID-19. If they wish to stay on the job, they have no choice but to adopt and innovate. If they can't cope with the sudden shift, they may have to leave. Some did decide to leave and not be bothered with all the e-learning hype.

While some laggards left the teaching profession, others that remained on board struggled to make their ERTL relevant and worthwhile. Learning must strike the meaningful chord in the hearts of students - that is the principle held dearly by these educators, but it is not easy to accomplish this impact when every single tool is new and every single task is technical. The point is--ICT did not just appear in the educational landscape a year before COVID-19. It has been around for more than 30 years.

As a refresher, let's go back to the computer history timeline. Charles Babbage created the first computer [the ENIAC] in 1822. Grace Hopper wrote the first programming language, COBOL, in 1953. Steve Jobs produced the Apple computer in April, 1976. Windows greeted the world in 1985. Tim Berners-Lee developed the World Wide Web in 1990. Tim O'Reilly and Dale Dougherty made Web 2.0 popular in 2004.

In Malaysia, computers have been making their way into schools since the late 1990s [1997, to be specific] through our Smart Schools programme. And fast forward to recent times, e-learning has been a feature in our higher education since 2006. Our national e-learning policy (DePAN 2.0), in fact, was officially announced to the public on April 16, 2011. In short, our path towards e-learning and online teaching was made clear and explicit more than nine years ago.

In hindsight, we had ample time to equip ourselves with basic online teaching skills, yet when COVID-19 struck, we found ourselves totally unprepared. I recall the frantic workshops we had at our kulliyyah on how to use Zoom and Google Meet and how to convert PowerPoint slides into videos and screencasts. It struck me that these are pretty basic skills--we should have been prepared with them long before COVID-19. But we were not, unfortunately.

The pandemic has indeed exposed the inadequacies in our education systems - from vision and planning, to competency development, to access to good bandwidth and wellfunctioning computers, to proper spaces and environments for online classes, to the technical support needed for staff training, and to faculty's not having the slightest idea of how to assess student learning online. The issues are important and diverse, and university leaderships must examine and iron them out with a visionary approach and deployment of pragmatic strategies. Because as things currently stand, it doesn't look like COVID-19 will go away any time soon.

In my view, not all about COVID-19 is bad. As a university teacher myself, I see a silver lining and very many blessings in the crisis, one of which is the blessing of new knowledge and skills. Forced by the situation to learn how to teach just as well online, many of us grew in our 
grasp of digital technology, and how it can be deployed to produce wonderful learning outcomes. We improved in our ability to use technology in many interesting ways. We discovered how a virtual wall could be turned into amazing e-portfolios, and how the various Google apps could galvanize impressive student collaborations. In an instructional design course I taught during the lockdown, students collaborated over Google Slides to create storyboards for their video projects. The outcomes were mind-blowing.

In the ERTL activities we did last semester, plenty of positive collaboration took place, plenty of creative thought and expression was shared, and plenty of multi-faceted communication was exchanged. These are three of the four main skills emphasized in $21^{\text {st }}$ century learning. Perhaps we were not too big on critical thinking - the fourth skill. This will need to be worked on substantially more in the next ERTL plan. But essentially, at the end of the journey, we actually got a glimpse of what $21^{\text {st }}$ century education may look and feel like.

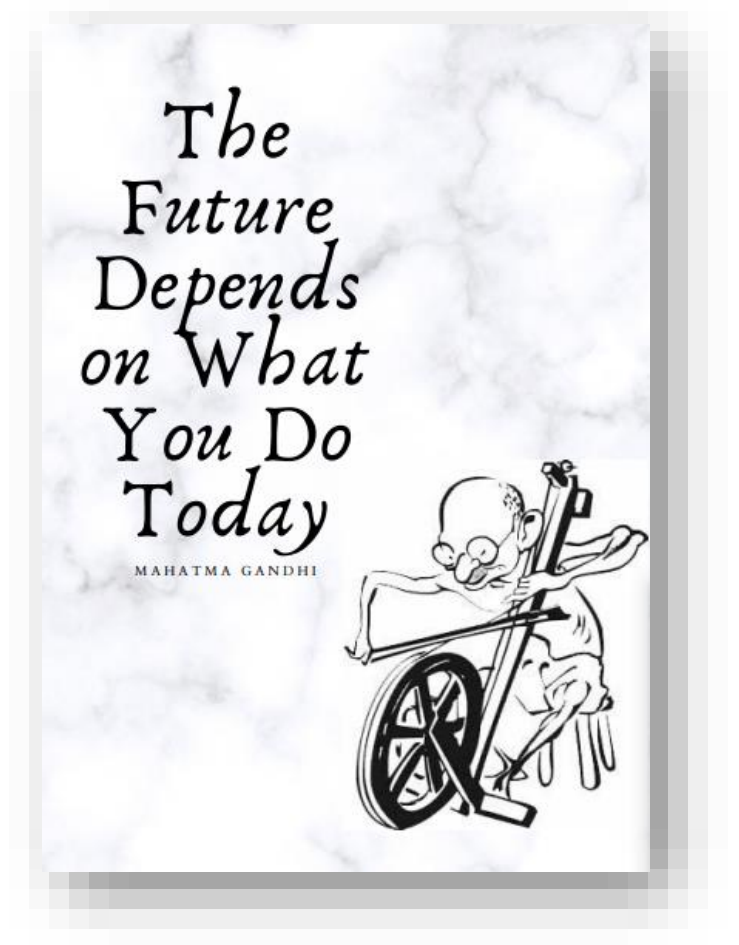

A touch of creative expression by an undergraduate student in my Information Technology class. This simple poster was created using the CANVA graphics app. Credit to $\mathbb{C}$ Ahmad Syahamin Mujei 2020

To me, COVID-19 has taught many of us teachers the value of thinking outside the standard boxes. For me personally, it has really opened wide the door to creativity and innovation in online teaching. If it wasn't for COVID-19, we probably wouldn't have realized how creative we could actually be as teachers. I guess we would still be in our comfort zones teaching didactically just as we were taught 40 or 50 years ago.

Ironically, thanks to COVID-19, we got to discover alternative ways of teaching and of learning that are pleasantly different from what we are used to. Thanks to coronavirus, the time for change, creativity and innovation in our teaching has finally arrived. So, wake up and smell the coffee. And be the difference you want to see in the world.

Assoc Prof Dr Tunku Badariah Tunku Ahmad

Editor of IIUM Journal of Educational Studies (IJES),

Kulliyyah of Education,International Islamic University, Malaysia.

tbadariah@iium.edu.my

October 4, 2020 